\title{
Resignificar el mestizaje tierra adentro Aguascalientes, Nueva Galicia, siglos XVII y XVIII
}

Salvador Camacho Sandoval (iD http://orcid.org/0000-0001-8065-5530

Universidad Autónoma de Aguascalientes, México

camacho_sal@yahoo.com.mx

Víctor González, Resignificar el mestizaje tierra adentro Aguascalientes, Nueva Galicia, siglos XVII y XVIII, México, Universidad Autónoma de Aguascalientes, 2018.

\section{Repensar la mexicanidad desde la negritud en el mestizaje}

El nuevo libro de Víctor González es el resultado de una investigación de varios años de reflexión, búsqueda de información y diálogo crítico con autores del pasado y el presente. En él se condensan de manera sintética y amigable debates historiográficos nada fáciles, reflexiones teóricas, análisis comparativos de regiones y, de manera especial, una recopilación acuciosa de datos en diversos archivos sobre la vida de los grupos afrodescendientes en la región centro occidente de México, atendiendo particularmente la Villa de Nuestra Señora de la Asunción de las Aguas Calientes y sus vínculos con el Bajío, los Altos de Jalisco y el norte, especialmente Zacatecas, por su importancia minera. De allí su atención a "Tierra adentro", diferente a las costas y al centro, un gran espacio geográfico que, citando a John Tutino, fue clave no sólo para el imperio español, sino para la construcción del capitalismo mundial.

\section{(c) (i) (8)} No-Comercial 4.0 Internacional.

Secuencia. E-ISSN 2395-8464 http://secuencia.mora.edu.mx/




El libro tiene como eje central "el estudio del mestizaje frente a la concepción tradicional del estudio de españoles e indígenas, teniendo como propuesta dar a conocer la relevancia de los afromestizos o, de acuerdo con un término de época, de las castas”, o “cualidades”, en la conformación de una nueva sociedad y de un "nuevo mundo”. El autor defiende la idea de que si queremos hablar del mestizaje debemos incluir la presencia de una destacada población africana que se fue mezclando a través de los años, a pesar de los impedimentos legales y culturales de los españoles.

Llaman la atención los acercamientos disciplinares que tiene el libro, pues en él hay historia demográfica, historia social y de la cultura, microhistoria, historia de las emociones, historia del arte, incluso un estudio de caso, buscando una perspectiva de género. El autor pone en el centro de la discusión los temas del deseo, la sexualidad y la intimidad, porque en los hechos, dice, el deseo sexual propició las mezclas, a pesar de que la ley ilustrada prohibía las relaciones entre castas. Aquí se busca un diálogo entre la Historia y la Psicología para entender esos mecanismos por los cuales hombres y mujeres de diferente origen se unieron no sólo para satisfacer deseos sexuales, sino también para conformar nuevas familias, transgrediendo patrones culturales de la época. Contra la presenta pureza de sangre, surgió con vigor en el siglo XVII una nueva sociedad que definiría "la mexicanidad”.

El deseo sexual, ese “oscuro objeto” de Luis Buñuel, es clave para entender el mestizaje. Para fundamentar esta tesis, Víctor González se remite a un estudio de Edward Shorter, Written in the Flesh: A History of Desire, publicado en la Universidad de Toronto en 2005. Contrario a la idea de Norberto Elias, de que el "proceso civilizatorio" se explica por el grado de disciplina y, sobre todo, autodisciplina; Shorter, por el contrario, sugiere que el deseo tiene implicaciones en la historia de la sexualidad; ciertamente, "un tema que requiere mayor profundización”.

Secuencia. E-ISSN 2395-8464 
Al mismo tiempo, se empeña en cuestionar la "idea criolla", que surgió en el siglo XIX y continuó en la posrevolución, al pensar el mestizaje como la unión de indígenas y españoles, "la raza cósmica" de José Vasconcelos, como un distintivo fundamental del nacionalismo mexicano. Por eso la insistencia de "resignificar el mestizaje". También señala que esta historia del pasado es historia del presente, porque las sociedades contemporáneas son cada vez más plurales, por lo que aferrarse a posturas rígidas que defienden razas puras, es ser ignorantes e intolerantes, lo cual conduce a la discriminación y al racismo. Completamente de acuerdo.

El libro contiene ocho ensayos, producto de esta investigación de largo aliento, los cuales tienen un eje común, pero pueden verse de manera independiente. El primero, “Aguascalientes Tierra adentro”, es de contexto: la creación de la Villa de las Aguas calientes, a partir de tres fenómenos relevantes: uno, el paso de uno de los tres Caminos reales de Tierra Adentro (de Ciudad de México hasta Zacatecas y luego a Nuevo México); dos, la expansión ganadera y los grandes latifundios, y tres, la "correlación con la producción minera neogallega y zacatecana”.

El segundo capítulo, "Poblamiento y expansión en el norte. El factor castas", está dedicado a la composición social de la parroquia de Aguascalientes en el siglo XVII, que incorpora a las castas como un elemento central, en especial a los afrodescendientes. Aquí, Víctor González hace un estudio de microhistoria sobre la ciudad para analizar el lugar que ocuparon las castas (negros, mulatos, zambos, lobos, coyotes...). Llega a la conclusión de que estos grupos llegaron a representar el 55\% de la población de Aguascalientes.

El tercer capítulo es un análisis de un caso excepcional: la manumisión o liberación de la esclava María Guadalupe, a partir de que demandó su libertad por incumplimiento de promesa. Ella tenía de 18 años y aceptó hacer "favores sexuales" a su amo, Domingo Antonio de Aguilera, de más de 70 años, a cambio de su libertad, promesa que no cumplió. Con el Secuencia. E-ISSN 2395-8464 
apoyo moral de su madre y la ayuda de un sacerdote y un abogado, María Guadalupe demandó y se careó con su amo, usando un sistema de justicia que lo permitía, en un contexto en el que, en los hechos, el poder de la Corona no era absoluto.

El siguiente capítulo se titula "La erosión de la endogamia o de la dinámica del mestizaje, siglo XVII y XVIII”; en él se analiza la intervención de los grupos afrodescendientes en la dinámica poblacional de la Nueva España y, en particular, de la Villa de Aguas Calientes. De allí la importancia de la cita de Serge Gruzinski, que está como epígrafe: "Las mezclas y los mestizajes pierden el aspecto de un desorden pasajero para convertirse en una dinámica fundamental”. A partir del análisis de caso, el autor sostiene que entre los españoles y los indígenas se procuró perpetuar su origen étnico llegando a tener uniones endogámicas, a diferencia de las castas, pero que, con el tiempo, aquéllos fueron abriéndose a la conformación de parejas mixtas, casadas o no legalmente. Para sostener esta afirmación, Víctor González consultó miles de registros en un periodo de doscientos años, de 1602 a 1800, y llegó a la misma conclusión que Alexander Humboldt, cuando visitó Colombia, Perú y la Nueva España: en estos lugares había un extraordinario crisol poblacional y de ellas surgirían las nuevas naciones, entre ellas México. Pudiéramos decir, entonces, que ese "oscuro objeto del deseo", más que los códigos prohibitivos y la tradición del honor y la "limpieza de sangre”, volvió a triunfar.

Siguiendo con la misma tesis, en el quinto capítulo se enfatiza la idea de que lo flexible e ilegítimo en la colonia permitió el mestizaje, y que los afrodescendientes, que eran "personas miserables", "las personas más pobres”, llegaron a ocupar un papel protagónico en este proceso de hibridez. Con el corpus de información de dos siglos, extraídos de archivos parroquiales, Víctor González analiza las uniones matrimoniales para el caso de Aguascalientes, así como "la ilegitimidad asentada en los registros de bautizos, a partir de un Secuencia. E-ISSN 2395-8464 
análisis serial y de largo plazo" durante este periodo. De lo que sucedía, el virrey Fernando de Alencastre, a inicio del siglo XVIII, dijo que las diferentes castas habían caído en degenere e inclinaciones viciosas. En esto había "adulterio y otros ilícitos", pero también acuerdos y matrimonios legítimos, que se incrementaron cada vez más con el paso de los años. Víctor González nos dice que en el presente otra vez se vuelve a tener hijos de parejas mixtas y sin el deseo de contraer matrimonio, como ocurre en Suecia. De aquí el título: "El futuro en el pasado. Sobre ilegitimidad y mestizaje”. En este capítulo hay un análisis sobre la Ley Pragmática Sanción de la corona española de 1776-1778, la cual ante "el desorden”, (lo “champurro") y "el abuso de contraer matrimonios desiguales", se obligaba a los hijos e hijas menores de 25 años a pedir consentimiento de los padres, so pena de perder derechos de herencia o a pedir dote.

El sexto capítulo trata sobre "Las crisis de mortalidad en los siglos XVII y XVIII", dentro de una perspectiva de la historia demográfica y la historia comparada, siguiendo a Marc Bloch. El centro es Aguascalientes y la crisis de 1785-1786, para lo cual se asumen varias categorías de análisis: parroquias, "calidades”, género y edad. Aquí llama la atención la insistencia del autor por analizar y comprender las causas estructurales y profundas que llevaron a estas crisis; por ejemplo, el mal funcionamiento del mercado, no sólo de alimentos, sino también de la tierra, el trabajo y los créditos, agravado por escasez de agua y otras tragedias naturales. A lo que hay que agregar la corrupción de una élite que aprovechaba esta tragedia para enriquecerse aún más, sin importarle las personas que morían de hambre. Fueron precisamente los negros y sus descendientes quienes más resistían los embates de la crisis.

El séptimo capítulo, "Hogares, familia y estratificación en Aguascalientes, 1792", el autor hace un análisis minucioso de la estructura familiar. Para ello, clasifica a los "grupos domésticos" (1. Solitarios, 2. Sin familia, 3. Casas familiares simples o nucleares, 4. Casas Secuencia. E-ISSN 2395-8464 
familiares extendidas, 5. Casas familiares múltiples, y 6. Indeterminada). Luego descubre cómo se distribuyeron espacialmente, para lo cual usa el mapa que elaboró Isidoro Epstein en 1855. Llega a la conclusión, entre otras, que el $85 \%$ de la población pertenecía a las familias nucleares de mulatos y castas, que eran las más pobres, y que las familias extendidas eran las familias ricas que vivían en el centro de la ciudad.

En el último trabajo, "Las pinturas de castas o del oscuro objeto del deseo”, Víctor González nos ofrece un ensayo que ha venido enriqueciendo desde hace años y que, por lo mismo, mantiene una discusión de vanguardia en la frontera del conocimiento con quienes han trabajado el tema. No se trata de un análisis de la obra de arte únicamente, que ya es mucho decir, sino de ver estas pinturas como una expresión de cambios radicales en la vida social y cultural en la colonia. Por ello, el autor discute argumentos presentados por otros historiadores, busca documentos antiguos para saber quiénes solicitaban la obra y a quiénes iban dirigidas, hace análisis ideológico y estético, interpreta y propone. Esto era expresión de que la sociedad colonial había cambiado, pues la gente se mezcló, se "degeneró”, se hizo “champurro” y perdió “pureza”. Las ideas ilustradas chocaron con el mundo de las emociones, se revaloró lo local y la pluralidad de las culturas, no hubo una sola verdad y por medio del barroco se abrió la puerta hacia “el pueblo”, a la trasgresión y a la alteridad. Frente a la idea de la “degeneración” y lo “inmoral” de las especies en América, las pinturas referían y refieren todavía, según palabras del autor, a "una tierra fértil con deliciosos frutos y un mestizaje vigoroso creador de hermosas criaturas”. Surgía la mexicanidad y se comenzó a tener conciencia de ello.

Finalmente, habrá que mencionar que, como ocurre con algunas buenas investigaciones, en este libro se hicieron preguntas globales y se respondieron localmente. Además, la flexibilidad disciplinaria y el arrojo metodológico son características que habrá que Secuencia. E-ISSN 2395-8464 
valorar y reivindicar, porque los resultados se multiplican y son sobresalientes, más allá de una fragmentación temática y desbalances en su tratamiento. 